\title{
Sociomaterial texts, spaces and devices: questioning 'digital dualism' in library and study practices
}

\author{
Lesley Gourlay
}

Culture, Communication \& Media, UCL Institute of Education, University of London, l.gourlay@ioe.ac.uk

Donna M. Lanclos

University of North Carolina at Charlotte, dlanclos@uncc.edu

Martin Oliver

Culture, Communication \& Media, UCL Institute of Education, University of London, m.oliver@ioe.ac.uk

\begin{abstract}
Work on students' study practices posits the digital and material as separate domains, with the 'digital' assumed to be disembodied, decontextualised and freefloating, and spaces in the material campus positioned as prototypically 'traditional' and analogue. Libraries in particular are often characterised as symbolic of predigital literacy practices and forms of meaning making. This binary oversimplifies student engagement, particularly in relation to their creation of and interactions with texts. Two studies illustrate this: an investigation of student and staff textual practices that explored the complex and emergent networks they created, adapted and maintained; and one that explored perceptions and use of library spaces (digital and physical). A sociomaterial analysis shows the ongoing importance of institutional, personal and public spaces. This demonstrates that in order to enhance the student experience, a more nuanced understanding of the complex, emergent relationships between digital and print, device and user, and author and text is required.
\end{abstract}

\section{Keywords}

Higher education, libraries, ethnography, digital dualism, sociomateriality, study practices, study spaces.

\section{Introduction}

Mainstream work on student study practices tends to posit the digital and the material as separate domains, a conception sometimes characterised as 'digital dualism' (Jurgensen 2011). In these accounts, the 'digital' is often assumed to be a somewhat disembodied realm, decontextualised and free-floating (Land 2005). In contrast, spaces in the material campus are frequently positioned as prototypically 'traditional' and analogue. Perceptions of libraries in particular as traditional and analogue spaces are persistent (De Rosa, 2005; Gauder, 2011). In this framing, library buildings and services frequently symbolise pre-digital literacy practices and forms of meaning making, and are assumed to be qualitatively different to more recognisably 'digital' spaces, even as such separation is belied by the evidently mixed digital and material practices of students and academic staff (Connaway et al., 2013). 
In applied educational research, the goal is to inform practitioners and policy makers in order to 'make a difference'; in this case to the quality and nature of the student experience of independent study, arguably an under-researched but vital area of student life.

This paper will argue that this assumed binary misunderstands students' practices, and thus can lead to distortions and oversimplifications in how student engagement is viewed, particularly focusing on the ways in which students interact with and create academic texts. As a primary locus of textual engagement (the sourcing, selection, downloading, reading, notetaking, writing and general interaction with texts) the library (both physical and digital) is a key site of enquiry into how this engagement unfolds in the detail of day-to-day study practices. As a consequence, it is important to develop a new understanding of what library use consists of, and propose a sociomaterial framing as a way of achieving this: that is, a framing that recognises the importance of the material as an essential component of the social.

This argument will be developed by reviewing critiques of digital dualism, exploring the literature on users' experiences of library, and then presenting empirical work that focuses on the complex, day-to-day practices that emerge in the practices of students and staff.

\section{Background}

The idea of digital libraries suggests a discontinuity, a break from traditional libraries. Such new terminology helps to focus attention on a developing phenomenon, but, this paper will argue, does so by neglecting commonalities and continuities. At the heart of this issue is the idea that the digital is sharply different from the social and material world (Jurgensen, 2011).

Although historically grounded accounts exist that show continuities between existing library infrastructures and contemporary scholarly practice (Borgman, 2007), the 'either/or' logic of 'digital dualism', which assumes that practices are either fully digital or analogue, has become the dominant paradigm in library evaluation. Libraries tend typically to be understood and evaluated against quantified models consisting of key performance indicators (Gonçalves et al., 2007). Such indicators differentiate between physical, traditional library spaces and uses of the digital library, building on assumptions about 'the 'digital' nature of digital libraries Gonçalves et al., 2007: p. 1417), rather than exploring users' actual experiences and practices, which may in fact transcend and breach this apparent boundary. These assumptions are so fundamental that authors such as McCray \& Gallagher (2001) slipped between 'the digital library' and 'digital library systems' in an apparently unproblematic way, as if the library were nothing other than the digital, technical systems that constitute it. This move reduces the library to a technical infrastructure; it ignores cultural, phenomenological and even material ways of understanding what libraries are. As Miller \& Horst (2012) argued, focusing on the novelty of the digital can result in a romanticised view of pre-digital cultures, ignores the materiality of digital practices and can result in naively normative accounts of practices.

Such accounts of library use illustrate the problems that Saunders (2014) raised about the usability of research outputs: while they may be well suited to quantitative monitoring and benchmarking, they presume a stable point of reference, an agreed understanding of practices and where they are enacted. They appear to objectify experiences by artificially tidying-up how they are accounted for, rather than reflecting the meaningful, messy and emergent way 
in which practices develop. By doing so, quantified standards hide the complex interplay that exists between purposeful social action and the material environment. These accounts therefore present social practice as if its direction is inevitable, as if the addition of technology will lead deterministically to an improved future, with a simplistic causal model underlying the quantification (improving scores causes 'goodness'). However, such models do not even identify the mechanisms through which scores might be improved. Even if such approaches manage to flag the shortcomings of a digital library, they would not help address them; there is no scope for the evaluation to 'talk back' to the model itself, developing it in the light of new evidence. Consequently, it is argued, such models tend to be used in ways that are confirmatory rather than evocative, assuming conceptual closure in order to act in a laboratory-like manner, rather than working with the 'provisional stabilities' that emerge from studies of practice (Saunders et al., 2005: p. 42). The concept of provisional stabilities is particularly helpful in moving beyond the closed, abstracted quantifications of practice, which, by hiding the social and material conditions under which they were enacted, treat social practices as if they were universal and timeless, cultureless and ahistorical. It highlights that, with sufficient detail, social practices can be understood in relation to the wider material and technical infrastructures that surround them, without lapsing into the assumption that either the social or the technical should be understood as the driving, determining force.

A parallel tradition of library evaluation work has developed that pays greater attention to what users do with digital libraries. Such work still succumbs to dualist critiques, assuming a sharp divide between digital and traditional libraries (possibly allowing for hybrids), but does at least recognise that user experience, not just system performance, is a possible component in the evaluation of digital libraries (Saracevic, 2000). Whilst such work often still assumes that users' experiences are quantifiable (in Saracevic's case, by specifying user experience with reference to criteria that can be assigned levels), other areas of library research have begun to argue for the value of ethnographically-informed evaluation (Goodman, 2011), particularly if service improvement (rather than service monitoring) is a priority. These kinds of accounts, generated through ethnographic work and rich descriptions of day-to-day practices, allow the bridging between current practice and future possibilities described by Saunders et al. (2005):

An evaluation approach that provides captured rehearsals, examples, metaphors, typologies, vignettes, cases, accounts and platforms, ways of working, principles of procedures, routines, i.e. depictions and can both evoke and enable the experience of boundary crossing, provides provisional stability for change; that is to say, it acts as a bridge. (Saunders et al., 2005: p. 42)

Such accounts draw attention to the particularities of practices, and to the ways in which resources and infrastructures are taken up to enable them. This allows contrasts to be drawn between the accounts and local practices, revealing points of commonality and difference; supporting the development of theories, and generating ideas for new configurations of practice. As such, they form bridges between past practices and possibilities for development.

In developing such accounts, this tradition of work has also begun to question the assumed separation between physical and digital libraries, which are woven together in the day-to-day practices of library users. New work drawing on qualitative and ethnographic methodologies has begun to ask critical questions about the apparent simplicity of these assumptions, as studies of textual practice in higher education reveal a more complex picture. The 
preponderance of digital texts has been found to lead to radically different forms of reading and attention (Hayles 2012), while meaning-making practices in and out of formal education have become increasingly multimodal, in what Williams (2009) characterised as shimmering literacies. Levy (2003) has pointed out the fluid nature of both digital and analogue library texts, thus questioning this apparently clear boundary. Recent qualitative work on student practices has shown that instead of working in clearly-defined domains of the digital or the analogue, students create and curate dynamic, mobile and emergent networks which constantly combine and cross between digital and print-based practices, according to students' purposes and the surrounding contexts (Gourlay \& Oliver 2013). Further, dominant assumptions about the library have also been challenged by ethnographic work (Kim Wu \& Lanclos 2011, Duke \& Asher 2012, Foster \& Gibbons 2007), and the results of investigations into student and staff motivations to engage with technology (Connaway et al., 2011; Connaway et al., 2013). These qualitative research projects reveal the co-presence of digital tools and practices within physical library spaces, some provided by institutions, and some owned or engaged in by the students and faculty independently. Work developing sociomaterial perspectives on education (Fenwick et al., 2011) has also provided theoretical frameworks that are of utility in understanding such complex areas of practice, in which agency is distributed across a network that includes digital and print literacy practices, a range of nonhuman actors in the form of devices and other artefacts, spaces and temporal frames, in addition to the conventionally-recognised human social actors. This paper draws on this perspective to illustrate the complexities and challenges revealed by qualitative studies of students' practices.

\section{Methodology}

In order to illustrate how the digital and non-digital were intertwined in participants' day-today practices, data will be analysed from two studies that explored students' textual production from a socially situated, material perspective.

The first was a year-long investigation of student and staff textual practices (Gourlay \& Oliver, 2013). This study involved a dozen student volunteers, drawn from four groups of students: Postgraduate Certificate in Education (PGCE), taught Masters, distance, and doctoral. Participants were recruited to ensure diversity of gender; age; home, European Union (EU) or international; and full-time or part-time status. The students were asked to use iPod Touch devices to document their day-to-day practices and interactions with texts and technologies in a range of settings. This multimodal journaling produced drawings, photographs, videos and textual notes in order to reveal the situated, material character of textual practice. Library use in particular was a recurrent theme within these data. Participants assembled these, presented them to the interviewers and discussed them. Participants were encouraged to focus on the 'messy' micro-level day-to-day lived activities, networks, and the material or spatial aspects of practice: elements that may be 'tidied up' by more conventional forms of data collection, such as, stand-alone interviews, which rely on self-report and may lead to abstraction (Gourlay, 2010). The multimodal nature of the data was also designed to maximise rootedness in the practice, through a focus on images or recordings of everyday objects and processes. The visual data they generated were treated as objects of analysis in their own right (Pink, 2007) but were also used as stimuli for discussion, grounding the interviews in the specifics of students' day-to-day sociomaterial practices. Across the course of the interviews, students took increasing responsibility for the curation, presentation and interpretation of the data that they brought with them, providing a further point of reference for interpretation. 
In the second study, twelve maps were collected of student and staff 'learning landscapes' from four libraries spread over two institutions, one of which was the institution from the first study. The metaphor of landscape built on lessons learned from the first study, in which it became apparent that students' experiences of spaces was one that involved continuities, sequences and connections, rather than sharp divisions. This moved the discussion away from a narrow focus on individual spaces, which may be viewed in isolation, by evoking networks of spaces existing in a relationship with each other. Similarly, in the discussions of learning, participants were encouraged to consider their engagement with texts. The landscapes that were represented varied in complexity; some were local and relatively limited but many others were extensive, involving buildings, people, technology, modes of transportation, institutional spaces, commercial spaces and domestic places. As with the previous study, these maps became the starting point for interviews as well as being a source of visual data in their own right.

Both studies received institutional ethical clearance and followed approved procedures for informed consent, including guarantees of anonymity and confidentiality, and the right to opt out at any point.

Five examples from these projects have been chosen for analysis here, since they illustrate the variations seen across the two data sets. Necessarily, as case studies, this work reflects the specificity of students' practices within very particular contexts. For example, the students who participated in this work all had access to mobile digital devices, and the institutions provided networked access to digital library collections, as well as desktop computers and wireless local area network (Wi-Fi) within the institution itself that could be used to access these. This level of infrastructure will not necessarily be available to students studying in other contexts; although students have shown themselves capable of accessing digital materials even in settings where the infrastructure is extremely poor (Czerniewicz et al., 2009).

\section{Findings}

The image below was generated by a student to explain the processes through which he wrote an assessed text. Here, we focus on the images of books, stacks, classes, the student bar, screens, a USB stick, institutional logos, notebooks and so on; the text labels within Figure 1 are of secondary importance. 


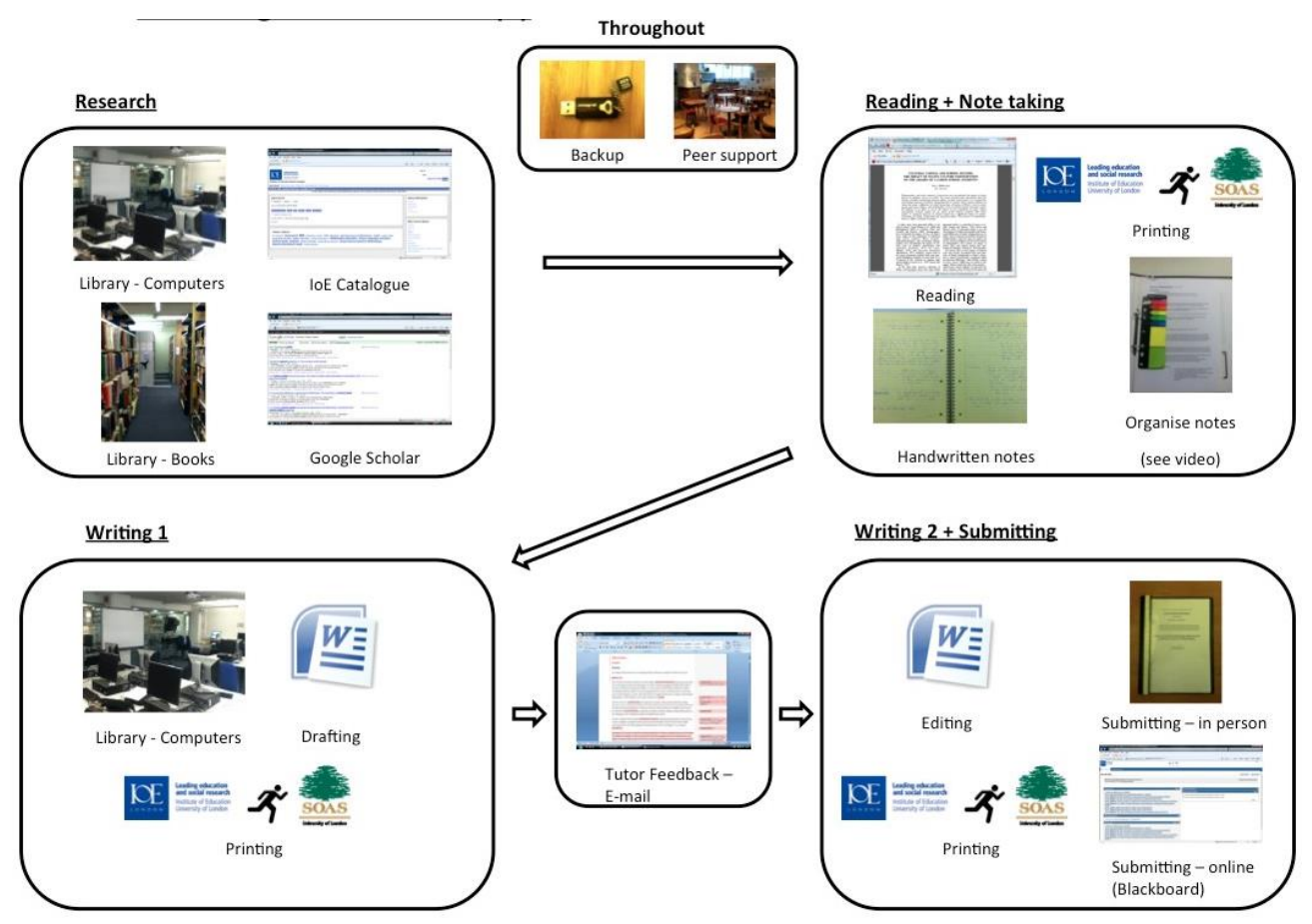

Figure 1: Juan's writing process (study one)

The juxtapositions are striking, with each step containing a mix of digital and physical elements. Material artefacts mingle with spatial domains as consistent elements in the writing process and texts exist in, and constantly shift between, both digital and print forms, whether through finding resources, authoring work or submitting the final piece. From the student interviews, it became apparent that the transition between digital and print marked important steps in the authoring process. For example, the printing of text that had been skim-read on screen to allow for closer engagement; the move from handwritten notes to a first wordprocessed draft; the highly symbolic printing and binding of the definitive dissertation at the point of submission.

Interestingly, in this example, the library is presented as segmented: one image for the computers, one for the books. In the interviews, this student's reported experiences seemed less clear-cut; there were iterative movements between computers and printed texts that did not divide neatly into these categories. However, the physical or digital aspects of library provision were foregrounded by the student at different points in the process. For example, browsing the physical shelves in an exploratory, scoping phase of work, as opposed to searching via the online library catalogue to confirm the details of a specific article when in the later stages of drafting work.

Further interview in the data set suggest that that the reasons these students locate themselves in particular places have less to do with the 'absolute' qualities of a particular place, and more to do with a complex calculus of motives, including not just their intentions at that time, but the surrounding context of their unfolding day. 


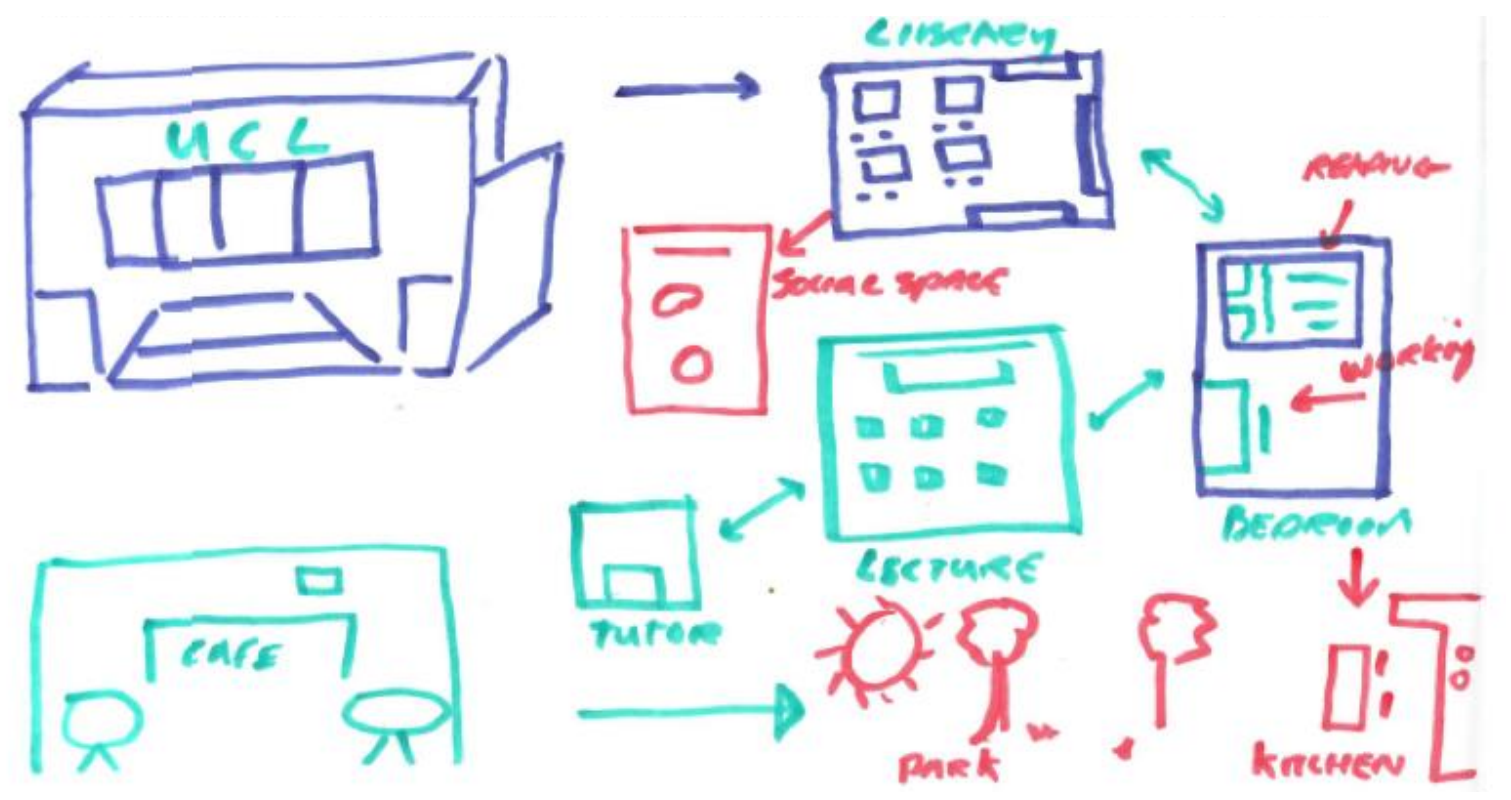

Figure 2: a third-year student's learning landscape (study two)

The map above (Figure 2) was generated by a third-year student. He has drawn the university on the left, and then broken it down into the various institutional spaces he visits for his academic work (the library, lecture halls, tutors' offices). These institutional spaces are embedded in a larger network of cafes, domestic spaces, and even (weather permitting) parks. This embedding reflects the specialisation of his uses of spaces; their purposes within the context of study are defined in part by the uses of other spaces, marking distinctions between areas of the student's life. This example illustrates the distributed nature of the student's practices, in which the library is one component in a larger network of interlocking settings.

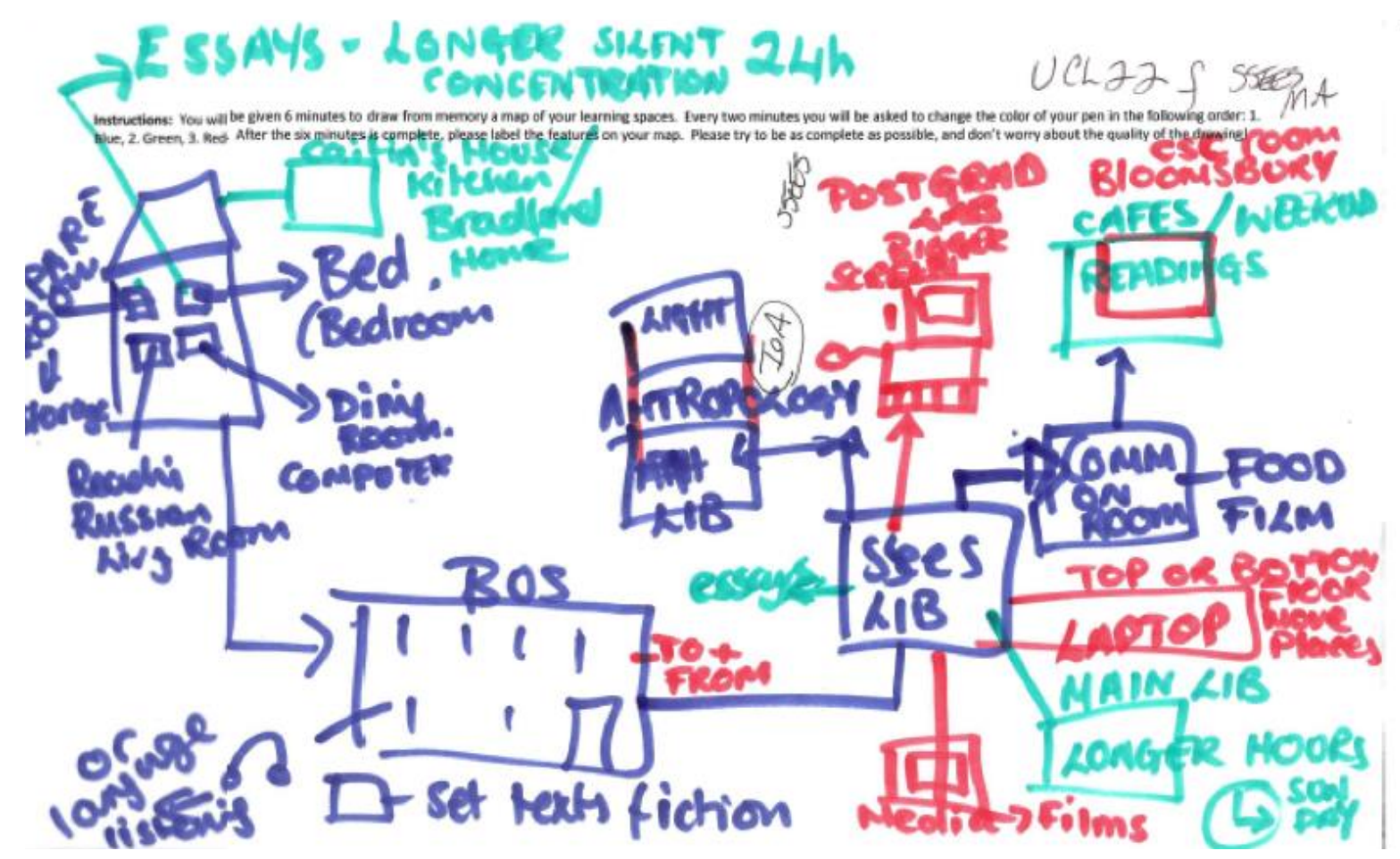

Figure 3: a postgraduate student's learning landscape (study two) 
An MA Humanities student has spaces all over London in her map (Figure 3, the small text at the top provides instructions for the task to the student). Her home has sub-areas she has identified for particular sorts of work, her commute on the bus is earmarked for certain sorts of reading or listening work, and the university part of her map includes not just the library (ostensibly, her academic 'home') but also a specialist library, the postgraduate common room, the main library, and various cafe spaces. She has featured her laptop among these university spaces as a crucial part of her landscape.

It is this laptop that enables her to move successfully from site to site; with it, she can recreate the environment she needs in order to study, bringing with her a personal library of digitised resources (her own, and institutional) that she can subsequently work with in the production of new texts.

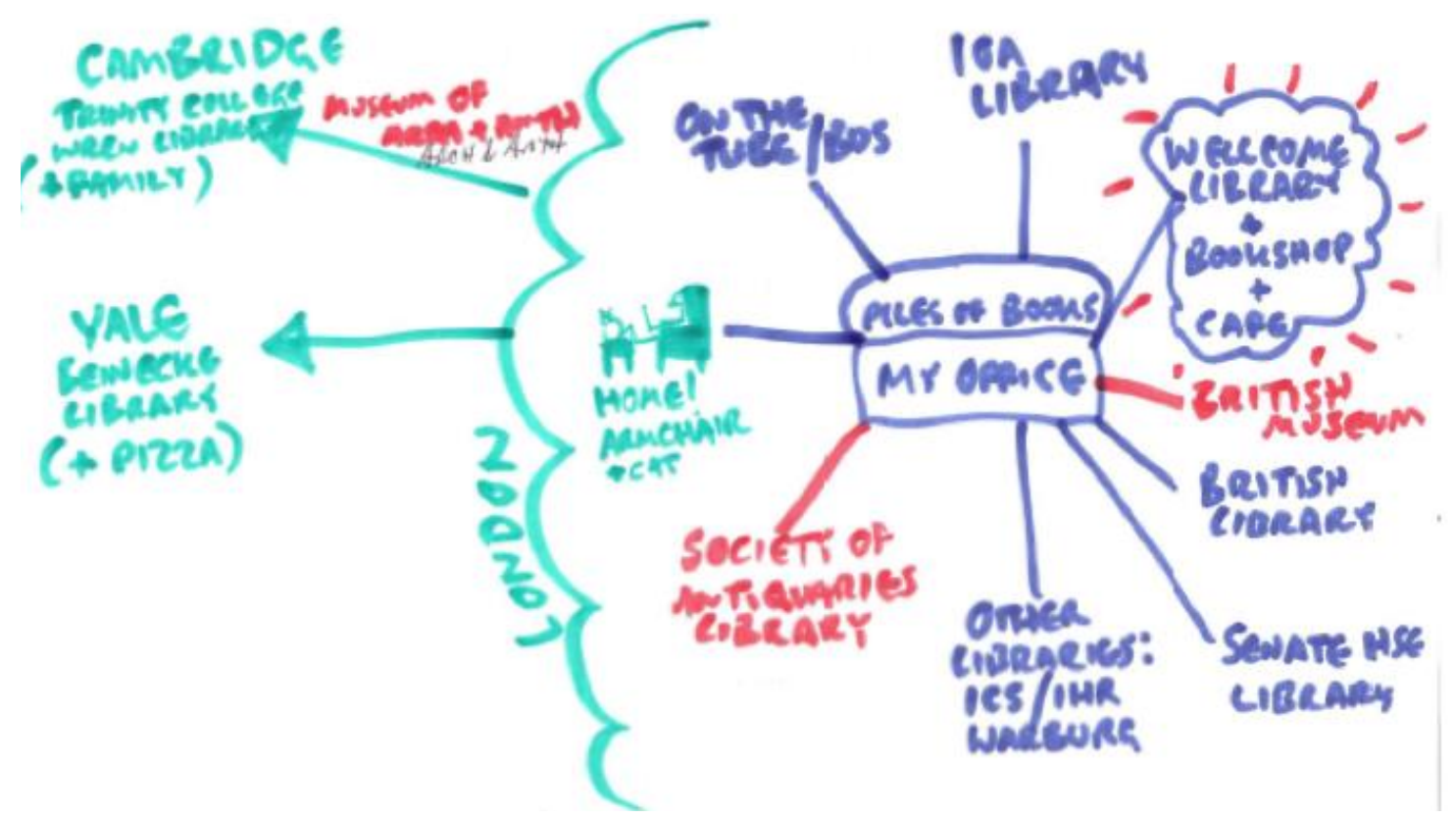

Figure 4: an academic's landscape (study two)

In this example, a member of academic staff has separated his London landscape from his other significant locations, and has included labels for London libraries (the British Library, Senate House, his specialist Library, and in particular the Wellcome Library, marked with red rays for emphasis), antiquity societies and museums, the Tube, and his office (Figure 4). He reports in his interview that Cambridge is important due to its connection to his brother as much as it is for its academic resources. Yale's Beinecke Library gains additional importance because of New Haven's pizza; this was one of many mentions of food, drink and sleep in the interviews, drawing attention back to the way in which studying is always an embodied practice. His home is represented by him in an armchair with his laptop and a catall of which underscore the widely distributed nature of his practices and the lack of any clear divisions between 'work' and 'home' or 'leisure'. The relative lack of specific representations of 'the digital' is also noteworthy. There are some devices depicted (computers, iPods, phones), and occasional representations of services, such as Dropbox or Evernote, but in general, the digital appears to permeate all of his networks of practice but is not marked as distinct from it. Again in this example, the library can be seen as intermeshed in a complex network of spaces where study practice emerges, which may be public and transitory, or intimate and domestic. 


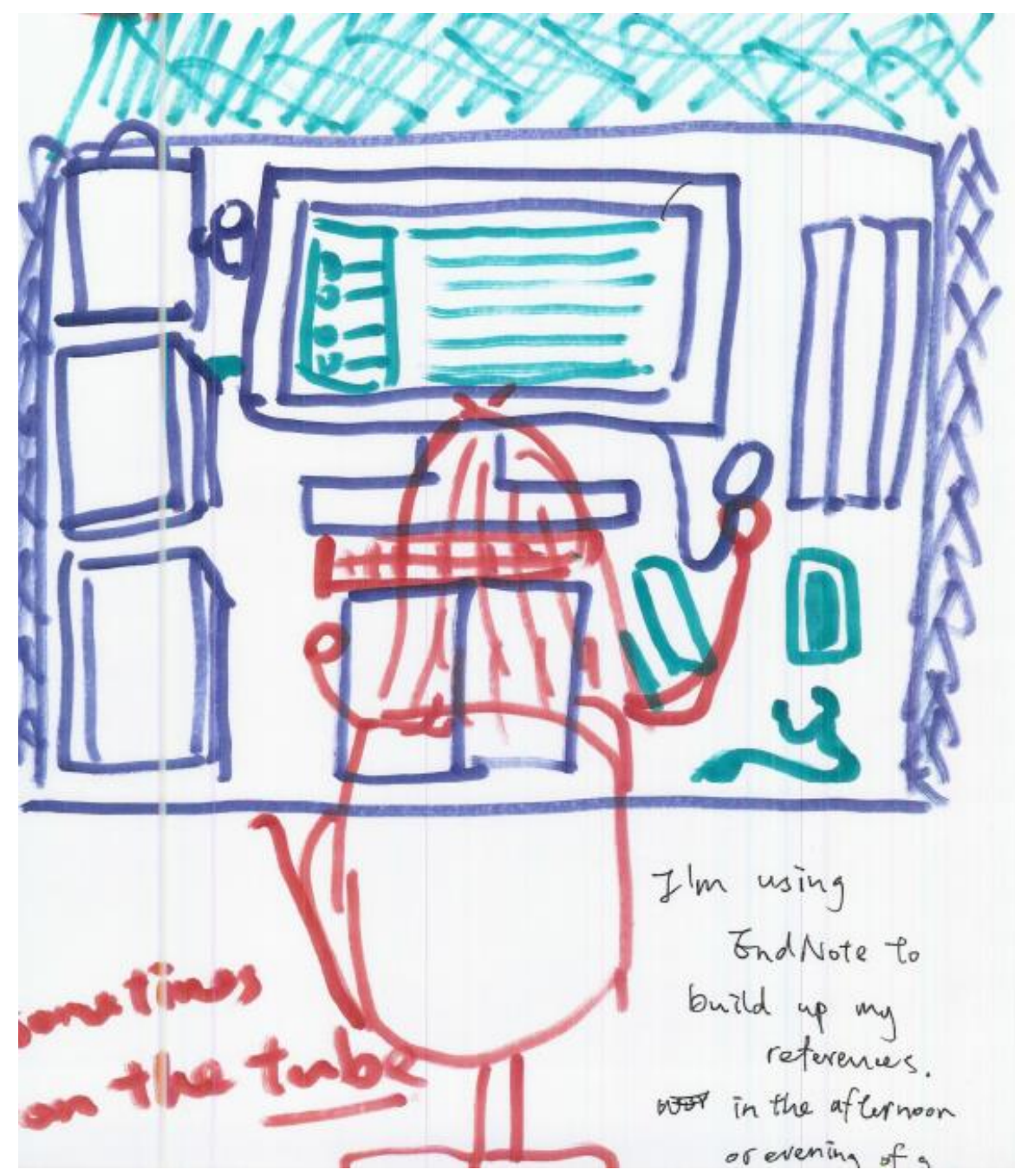

Figure 5: a postgraduate student's learning landscape (study two)

Finally, one postgraduate student has represented her entire study landscape within this single desk in a shared research students' room (Figure 5; the cropped text offers a commentary). While she does note that sometimes she studies on the Tube, the core of her work occurs here, at this desk. She states in her interview that this relates to the fact that she cannot use Endnote at home. Being 'tied' to the desk by this software need is not without its problems, because there is no actual formal assignment of desks, they are informally claimed, and the claim is recognised by her fellow students in the ways that she marks her territory with books, 'personal things' and her persistent presence in that space.

Yes, I leave some of our personal things, so...but in our room there's a few desks empty, so if any student just comes for one or two days, they need a computer... and they can sit there...or if the research room is full and maybe they will sit on my seat if I'm not there, because it doesn't belong to anyone. It's not my seat actually, but because I put my things there, so they won't choose my seat at first. They will choose an empty seat, yes, and I can make sure that when I come to the room I can have... Yes, so okay, a typical day, when I come to the research room and sit on my desk, it is normally two o'clock in the afternoon because I wake up, like, at 9.30 or at 10 and I have my breakfast and do some housework...not in my room, do something else, and then it takes 50 minutes from my home to the IOE, 
so when I arrive and I sit back, 2pm or 1.30, and I sit down and the first thing I would do is to make a cup of tea. So this one is the kettle. I think that is important for me, so I draw this.

The research room is a place this student can settle in at least in part because she is able to have tea, an important thing to her comfort, and so her ability to persist working at the desk is interwoven with the creation and maintenance of this highly particular embodied material space.

\section{Discussion}

The maps provided above might be characterised as 'post-digital' maps of practice, where the digital is implicit, and understood to be present or available across all aspects of practice, arguably instantiating Weiser's (1991, p. 78) point that: 'The most profound technologies are those that disappear. They weave-themselves into the fabric of everyday life until they are indistinguishable from it', a point also made by Dourish and Bell (2011) in their investigation into the ubiquity of the digital in day-to-day life. The data suggest then that for these students 'learning landscapes' are not just about physical spaces, but are complicated social networks of people, analogue and digital resources and nonhuman actors. These distributed, diverse networks of practice are to some extent 'visible', and map-able as physical places, their distributed nature made possible to a large extent as a result of digital mediation.

However, despite the ubiquity of the digital, it is also worth pointing out that these digital practices are always embedded in the material, with hunger, thirst, the desire for natural light, and other embodied needs emerging throughout the interview data. Switching back and forth between digital and analogue appears in the data to be a key part of students' learning landscapes. The maps also show the fragmented and unpredictable nature of these networks of practice. Participants' needs were seen to constantly shift depending on the work they are trying to do, the resources they have available, the time available, and the human networks they need to participate in.

The data reveal highly complex, idiosyncratic and emergent networks that the participants created, adapted and maintained, consisting of a range of devices, texts, and physical spaces with practices in constant interplay between the digital and the print-based. Throughout these practices, social actors engage in a form of complex ongoing bricolage, constructing emergent, ephemeral networks of sociomaterial practice that are in contract flux. This analysis serves to undermine notions of a strong dualism between digital and analogue practice in day-to-day study and academic practice, and therefore in typological characterisations of spaces, practice or social actors themselves.

\section{Conclusions}

Whilst it may be seductive to envisage a new, digital era of academic practice, and rhetorically powerful to position established approaches to study as 'old', this data suggests that students' study practices continue to be shaped in important ways by the physical spaces and resources with which they work. These exist alongside, and are intertwined with, the digital resources that they access, create, carry about with them on physical storage media or access from cloud storage via devices such as laptops or smart phones.

By drawing on sociomaterial perspectives (Fenwick et al., 2011), this paper has argued that a more nuanced understanding is required of the complex, emergent relationships between the 
digital and print, the device and user, and the author and text. By analysing the maps and accounts that students provided to explain their study practices, a more holistic picture has been provided of contemporary academic and study practices in the everyday flow of activity, and how that is configured within spaces, but also itself reflexively configures spatial and temporal domains.

This analysis provides fresh insights into study practices in digital and analogue spaces that challenge 'common sense' binaries of user and device, author and text and practice and context, undermining the neat classifications that have formed the basis for control-oriented library evaluation frameworks. By illuminating the complexity of emergent practices, this work can inform the development of library spaces, services and resources; their subsequent evaluation; and also research on the more distributed and highly complex nature of contemporary academic and study practices. Revealing the messy ways in which students have created provisional stabilities by taking up library infrastructures, subverting or misusing spaces, working around the barriers they experience, transforming texts from digital to print and back, and so on, serves several important ends. First, it can build a repertoire of 'case law' from which ideas about new developments can be drawn. Second, through generating this body of case-based narratives, it can support the development of more general theoretical insights into users' engagement with libraries. Third, it can be used to provide counter-examples, challenges to popular or well-intentioned proposals that risk failure to connect with the needs, expectations and preferences of actual users.

The constant intertwining of the physical and digital in students' experiences emphasises the importance of supporting students as they access, read, curate and create texts. The digital library has become an essential part of students' study practices; however, it does not define the totality of their experience. Students still need to sit, print, browse stacks, eat and sleep: whether they are engaging with the digital, with print literacy artefacts, or both. As researchers, librarians or educators it would be a mistake to lose sight of this. It is only by drawing on work at this level of nuance and granularity that it is possible to make a difference in this complex and fast changing area of student practice.

\section{References}

Borgman, C. (2007) Scholarship in the digital age. Information, infrastructure and the Internet. Cambridge, MA: MIT Press

Connaway, S., D. Lanclos, and E. Hood. (2013) I always stick with the first thing that comes up on Google... where people go for information, what they use, and why. EDUCAUSE Review Online. Available at: http://www.educause.edu/ero/article/i-always-stick-firstthing-comes-google-where-people-go-information-what-they-use-and-why. Accessed ? April 2015.

Connaway, L., White, D. and Lanclos, D. (2011) Visitors and residents: what motivates engagement with the digital information environment? Proceedings of the American Society for Information Science and Technology, 48(1), pp.1-7.

Connaway, L., White, D., Lanclos, D., LeCornu, A., and Hood, E. (2013) User-Centered Decision Making: A New Model for Developing Academic Library Services and Systems. IFLA Journal, 39(1), pp. 20-29.

Czerniewicz, L., Williams, K., and Brown, C. (2009). Students make a plan: understanding student agency in constraining conditions. Research in Learning Technology, 17(2), pp. $75-88$. 
De Rosa, C., (2005) Perceptions of libraries and information resources: A report to the OCLC. Dublin, OH: OCLC.

Dourish, P., and Bell, G. 2011. Divining a Digital Future: Mess and Mythology in Ubiquitous Computing. Cambridge, Mass: MIT Press.

Duke, L. and Asher, A. (2012) College Libraries and Student Culture: What We Now Know. American Libraries Association.

Fenwick, T., Edwards, R., and Sawchuk, P. (2011). Emerging Approaches to Educational Research: Tracing the Sociomaterial. Chicago: Routledge.

Foster, N. and Gibbons, S. (2007). Studying Students: The Undergraduate Research Project at the University of Rochester. Chicago; Association of College and Research Libraries.

Gauder, B.. 2011. Perceptions of Libraries, 2010: Context and Community. A Report to the

OCLC Membership. OCLC Online Computer Library Center, Inc.

Gonçalves, M., Moreira, B., Fox, E. and Watson, L. (2007). What is a good digital library? A quality model for digital libraries. Information Processing \& Management, 43(5), pp. $1416-1437$.

Goodman, V. (2011) Applying ethnographic research methods in library and information settings. Libri, 61, pp. 1-11.

Gourlay, L. (2010) Multimodality, visual methodologies and higher education. In SavinBaden, M. \& Howell Major, C. (Eds.), New Approaches to Qualitative Research: Wisdom and Uncertainty, London: Routledge. pp. 80-88.

Gourlay, L. and Oliver, M. (2013) Beyond the social: digital literacies as sociomaterial practice. In R. Goodfellow and M. Lea (Eds.) Literacy in the Digital University: Critical Perspectives on Learning, Scholarship and Technology. London: Routledge, pp.79-94.

Hayles, K. (2012). How We Think: Digital Media and Contemporary Technogenesis. Chicago: University of Chicago Press.

Jurgensen, N. (2011). Digital dualism and the fallacy of web objectivity. Cyborgology http://thesocietypages.org/cyborgology/2011/09/13/digital-dualism-and-the-fallacy-ofweb-objectivity/. Accessed? April 2015.

Kim Wu, S. and Lanclos, D. (2011) Re-imagining the users' experience: an ethnographic approach to web usability and space design. Reference Services Review, 39(3), pp. 369389.

Land, R. (2005) Embodiment and risk in cyberspace education. In R. Land and S. Bayne (Eds.) Education in Cyberspace, London: Routledge pp.149-164.

Levy, D. (2003). Documents and libraries: a sociotechnical perspective. In A. Peterson Bishop, N. Van House, and B. Buttenfield (Eds.) Digital Library Use: Social Practice in Design and Evaluation. Cambridge, MA: MIT Press, pp. 25-42.

McCray, A. and Gallagher, M. (2001). Principles for digital library development. Communications of the ACM, 44(5), pp. 48-54.

Miller, D. and Horst, H. (2012) The digital and the human: a prospectus for digital anthropology. In Horst, H. \& Miller, D. (Eds), Digital Anthropology, London: Berg.pp. 335.

Pink, S. (2007) Doing Visual Ethnography, $2^{\text {nd }}$ Ed, London: Sage.

Saracevic, T. (2000) Digital library evaluation: Toward evolution of concepts. Library Trends, 49(2), pp. 350-369.

Saunders, M. (2014) The use and usability of research outputs: making a difference. Think Piece, HECU7. Available at: http://www.lancaster.ac.uk/fass/events/hecu7/docs/ThinkPieces/saunders.pdf. Accessed April 2015. 
Saunders, M., Charlier, B. and Bonamy, J. (2005). Using Evaluation to Create 'Provisional Stabilities' Bridging Innovation in Higher Education Change Processes. Evaluation, 11(1), pp. 37-54.

Weisner, M. (1991) The Computer for the $21^{\text {st }}$ Century. Scientific American 265(3), pp. $94-$ 104.

Williams, B. (2009) Shimmering Literacies: Popular Culture and Writing Online. Amsterdam: Peter Lang. 